RELACult - Revista Latino-Americana de Estudos em Cultura e Sociedade

Revista Latinoamericana de Estudios en Cultura y Sociedad | Latin American Journal of Studies in Culture and Society

V. 04, nº 01, jan-abr., 2018, resenha $n^{\circ} 882$ | relacult.claec.org |e-ISSN: 2525-7870

\title{
Processos interdisciplinares para a releitura da condição salarial como questão social: analytical research da sociologia do trabalho na obra de Robert Castel
}

\author{
Procesos interdisciplinarios para la relectura de la condición salarial como cuestión social: \\ analytical research de la sociología del trabajo en la obra de Robert Castel \\ Interdisciplinary processes for the re-reading of the salary condition as a social question: \\ analytical research of the sociology of work in the work of Robert Castel
}

Arthur Saldanha dos Santos ${ }^{1}$

\begin{abstract}
Resumo
Este trabalho visa retornar às análises prescritas por Robert Castel, sobre a condição salarial. $\mathrm{O}$ autor tem como proposição central compreender as dinâmicas complexas e mutáveis que envolvem a condição salarial dos indivíduos, por assim dizer, que se contextualizaram ao longo da consolidação do capitalismo. Nessa perspectiva, assim como é desenvolvido em sua obra, dedica-se aqui em fazer um recorte de cunho interdisciplinar, tão necessário nos contextos atuais. Levando-se em consideração que a vivência da sociedade europeia se assemelha às distintas sociedades de base capitalista pelo mundo - com o cenário nada agradável de aumento considerável do desemprego, precarização da condição trabalhista, desigualdades sociais, marginalização, que perduram nos dias atuais.
\end{abstract}

Palavras-Chave: Capitalismo; Condição salarial; Interdisciplinar; Trabalho.

\section{Resumen}

Este trabajo pretende volver a los análisis prescritos por Robert Castel, sobre la condición salarial. El autor tiene como proposición central comprender las dinámicas complejas y mutables que involucran la condición salarial de los individuos, por así decir, que se contextualizaron a lo largo de la consolidación del capitalismo. En esa perspectiva, así como es desarrollado en su obra, se dedica aquí a hacer un recorte de cuño interdisciplinario, tan necesario en los contextos actuales. Teniendo en cuenta que la vivencia de la sociedad europea se asemeja a las distintas sociedades de base capitalista por el mundo, con el escenario nada agradable de aumento considerable del desempleo, precarización de la condición laboral, desigualdades sociales, marginación, que perduran en los días actuales.

Palabras claves: El capitalismo; Condición salarial; Interdisciplinario; Trabajo.

\begin{abstract}
This paper aims to return to the analyzes prescribed by Robert Castel, on the salary condition. The author's central proposition is to understand the complex and changing dynamics that surround the salary condition of individuals, so to speak, that have been contextualized throughout the consolidation of capitalism. In this perspective, as it is developed in his work, it is dedicated here to make an interdisciplinary cut, so necessary in the current contexts. Taking into account that the experience of European society is similar to the different capitalist-based societies around the world - with the unpleasant scenario of a considerable increase in unemployment, precariousness of the labor conditions, social inequalities and marginalization that persist in the present day.
\end{abstract}

\footnotetext{
${ }^{1}$ Doutorando em Sociologia na Universidade Federal do Rio Grande do Sul - UFRGS (Bolsista pela Coordenação de Pessoal de Nível Superior - CAPES). Mestre pelo Curso Associado entre a Universidade Federal de Minas Gerais (UFMG) e a Universidade Estadual de Montes Claros (UNIMONTES) em Sociedade, Ambiente e Território ( PPG-SAT). Bacharel em Humanidades pela Faculdade Interdisciplinar em Humanidades da Universidade Federal dos Vales do Jequitinhonha e Mucuri (UFVJM). E-mail: arthur-ufvjm @ hotmail.com.
} 
Keywords: Capitalism; Wage condition; Interdisciplinary; Job.

CASTEL, Robert. As metamorfoses da questão social: uma crônica do salário. Tradução de Iraci D. Poleti. 7. ed. - Petrópolis, RJ: Vozes, 2008, 611p.

Com uma perspectiva nada linear, Robert Castel em sua obra As metamorfoses da questão social: uma crônica do salário (7 $7^{\mathrm{a}}$ edição em 2008), tem como proposição central compreender as dinâmicas complexas e mutáveis que envolvem a condição salarial dos indivíduos, por assim dizer, que se contextualizaram ao longo da consolidação do capitalismo. Portanto, essa questão social compreendida como elemento de partida de sua análise, emerge e é guiada por um processo metamorfósico, ao menos pode ser entendida por esse viés ao longo de sua obra. Para desenvolver estas reflexões um tanto complexas e realistas desde sua época, Castel reflete, mundialmente, ou mesmo na abrangência transnational - se tratando de sociedades emergidas no fluxo contínuo do processo capitalista in globalization, aquilo que foi levantado pelos autores clássicos das questões trabalhistas: o ser humano envolto a um contexto dinâmico e nuclear de relações socioeconômicas. Dessa forma, suas percepções vão além da sociedade francesa in loco. A vivência da sociedade europeia se assemelha às distintas sociedades de base capitalista pelo mundo - com o cenário nada agradável de aumento considerável do desemprego, precarização da condição trabalhista, desigualdades sociais, marginalização, que perduram nos dias atuais.

Tais apontamentos se tornaram agenda de pesquisas para diversas áreas de estudos, como por exemplo, Sociologia, Economia, História, Demografia, entre outras. Estas observações corroboram com as perspectivas interdisciplinares da obra aqui analisada - que se baseou em análises diversificadas da condição salarial, transformando-a em crônica. Trabalhos como estes são fundamentais nos contextos mais atuais, dadas as circunstâncias dialógicas de conhecimentos múltiplos para um mesmo caso em questão. Dessa forma, a interdisciplinaridade busca unir conhecimentos distintos sobre um mesmo assunto. Para além da ligação entre as diferentes disciplinas (ou ciências), o processo interdisciplinar promove o aprendizado crítico-reflexivo dos indivíduos, aprimorando, portanto, a experiência do ensinoaprendizagem (LIBÂNEO, 1994; SALDANHA \& SILVA, 2017).

Essa discussão principiada na Europa (da obra aqui analisada), se tornou e ainda é parte fundamental das discussões que envolvem a agenda de investigação da sociologia do trabalho no Brasil. Para tanto, seria mais coerente nos referirmos a um aspecto mais amplo, propondo então pautas de investigações (plural investigations) da sociologia do trabalho, já que se perpetua nesse espaço de diálogo, questões diversificadas, específicas ou não, multifacetadas e, sobretudo, interdisciplinares, multidisciplinares ou mesmo, transdisciplinares (JAPIASSU, 1976; WEIL, 1993; DOMINGUES, 2005). Esse processo metodológico das formas de se fazer/construir uma sociologia mais dialógica na esfera acadêmica, na certa agradaria ao Castel. Autor este, que procurou estabelecer conexões em seus estudos com as diversas áreas do saber, que moldaram as noções trabalhistas ao longo dos milênios. Destaca-se nesse sentido, as interações com a História, Geografia, Antropologia, Economia, Demografia, dentre outras áreas de fundamental importância em seu constructo empírico e teórico. 
Embora Robert Castel tenha se lançado ao desafio de construir um trabalho diversifié na Europa, no Brasil este percurso urge na Sociologia do Trabalho. A analytical research deste, ou destes objetos, precisam se abrir mais ao amplo universo de produções científicas na área, não centrados na totalidade, mas sim nas análises múltiplas e complementares dos estudos em questão, principalmente se tratando de produções empíricas, como por exemplo, envolvendo populações rurais. Contudo, vale ressaltar que os passos primários fundamentados nos teóricos clássicos, e estritamente centrais nos debates dos condicionantes trabalhistas são profundamente inseridos, de modo geral, nas discussões acadêmicas brasileiras, o que podemos considerar na perspectiva de Castel como positivo, louvável e necessário.

Sem mais delongas, adentrando sumariamente ao produto de longos anos de estudos de Robert Castel, destaca-se de forma introdutória a estrutura básica a que sua obra está desmembrada. Para tanto, o livro se divide de forma estratégica em duas partes. Na primeira, o autor, por meio de um recorte clássico e fundamentalista, desenha a estrutura da formação trabalhista das sociedades tidas como primárias - processo este que ele nomeia "da tutela ao contrato". Na segunda divisão do seu trabalho ("do contrato ao estatuto"), Castel se dedica ao entendimento das complexidades envolvendo as relações sociais, vinculadas ao trabalho, ou a partir do trabalho, enviesadas pela modernidade ou, de forma concisa, moldadas pelas dinâmicas capitalistas em questão. Podemos considerar a conclusão de sua obra como uma divisão a parte (capítulo final), já que além de receber um título ("o individualismo negativo"), o autor procura abrir caminhos para questionamentos que perduram ao passar dos anos, estando presentes nas diversas discussões acadêmicas/científicas. Sem intenção de promover um spoiler, o autor nos leva a pensar em como a condição salarial poderá ser pensada no amanhã, uma vez permeada pelas relações, cada vez mais frequentes, de "uma sociedade de indivíduos" - promovendo o individualismo categórico, por assim dizer (p. 595).

Como introdução, o autor parte da conjuntura atual de sua vivência - temporalidade esta que infelizmente, não só localmente, tende a não transcender para formas mais positivas de progressão socioeconômica. Para problematizar suas investigações, ele discorre majoritariamente, a partir do "desemprego em massa e a instabilidade das situações de trabalho", tendo ainda como elemento não dissociável, "a inadequação dos sistemas clássicos de proteção para dar cobertura a essas condições". Elementos estes atrelados a um panorama mais geral e catastrófico, da "multiplicação de indivíduos que ocupam na sociedade uma posição de supranumerários, 'inempregáveis', inempregados ou empregados de um modo precário, intermitente" (p. 21). De modo mais específico, mas nem um pouco reducionista, o sociólogo francês delineia como aparato de estudo, "a desconversão social, o individualismo negativo, a vulnerabilidade da massa, a desvantagem, a invalidação social, a desfiliação...", dentre outros aspectos (p.23). Proposições estas imbuídas ou sendo representativas e originárias, nas transformações do mundo globalizado. Em síntese, seu foco fica explicito na introdução, com o cuidado minucioso de analisar as dinâmicas envolvendo a instabilidade social e a precariedade econômica, tão caras às sociedades - entendidos ainda, como a própria metamorfose da questão social, fenômeno este que se transforma na sociedade e é transformado por ela.

O traçado primário não poderia ser de outra forma, se não compreendendo as relações sociais, mais estritamente "a proteção próxima" entre os indivíduos. É nesse condicionante das organizações sociais mais complexas que Robert Castel se concentra no capítulo primeiro. A preocupação nas relações, estruturas e problemáticas envolvendo os indivíduos sociais por natureza, esteve presente ao longo dos estudos mais distintos das sociedades humanas. $\mathrm{O}$ sociólogo alemão Georg Simmel, por exemplo, em sua obra prima "Soziologie" de 1908 
apresentou para a sociedade alemã como a sociologia se constituiu, tornando-se referência fundamental nesse discurso e estabelecendo parâmetros para a elevação da sociologia enquanto ciência consolidada. Nos interessa, contudo, a sutileza e a primazia com que Simmel tratou as interações sociais presentes nos modos de vida grupal ou individual - ele por sua vez carregava uma certa influência da filosofia kantiana. É possível perceber na obra de Castel, de forma sequencial, uma "dose" nada moderada, da ideia de Vergesellschaftung (socialização) evidenciada por Simmel, que mesmo de forma sutil, se destacou nas discussões envolvendo a sociedade, se tornando por meio da corrente teórica do interacionismo, referência tanto para a Escola de Chicago quanto para a Escola de Frankfurt. Estes parênteses foi para evidenciar como a sociologia das interações se apresenta também em metamorfoses, mais estritamente, como Castel construiu seu aparato bibliográfico sobre as sociedades influenciando diversos outros autores, a se reinventarem a partir destas perspectivas - estabelecendo, portanto, de modo geral, releituras cada vez mais interdisciplinares das questões analíticas da sociologia, ao universo da História.

Ainda no capítulo supracitado, Robert Castel procura esmiuçar a noção de sociedades primárias, plural este atribuído pelo simples fato de existirem distintas configurações que se encaixam nessa esfera, bem como, não busca representar em uma totalidade as unidades sociais, mas levando em consideração as diversas desfiliações que ocorrem nas interações humanas. Nessa perspectiva, os indivíduos desfilados quebram as forças coercitivas que unem as pessoas nas linhas de proteção próxima, estabelecendo seus próprios parâmetros. Estas observações, atualmente compõem o escopo de estudos aprofundados, tanto na Sociologia, quanto nas pesquisas Demográficas - que se centram nas análises das redes sociais de interações humanas.

No capítulo segundo o autor desenha o traçado que vai guiar a transição das sociedades medievais para o feudalismo, e consequentemente, o eixo capitalista. Essas inclinações não muito sutis nem lineares, se deu na observância, sobretudo, das transformações envolvendo as atividades agrárias e urbanas. As diversificações desses espaços são vistas como indicadores das transformações experimentadas pelas cidades - e que inúmeros autores, inclusive Robert Castel, se dedicaram/dedicam a analisar. A especialização dos espaços, bem como, os parâmetros assumidos pela condição trabalhista nesse contexto, são debatidos pelo autor. Nessa perspectiva, noções como vagabundos, proletários, mendigo, centro e periferia, são chamados para compor um discurso tão necessário nessas mudanças das estruturas sociais, sejam no campo ou na cidade. $\mathrm{O}$ foco, contudo, será direcionado à complexa situação construída sobre como a condição salarial das populações se manifesta ao longo dos anos.

Tendo dito isso, Castel nos leva ao terceiro capítulo de sua obra, para refletir sobre a "indigna condição de assalariado" na modernidade (p.145). Este tópico, talvez o mais equilibrado de sua obra, por apresentar proposições de estudo e externalizar a gênese das problemáticas que compõe seu trabalho. A vulnerabilização é vista como o ponto de partida para as reflexões das manifestações das condições de indignidade salarial. Para o autor, "é nos processos de vulnerabilização que 'arruínam os pobres' que se deve buscar a origem das perturbações que afetam o equilíbrio social” (p. 147). Essa indicação metodológica, se podemos dizer assim, tem influenciado diversas pesquisas ao longo dos anos, bem como, tem sido à guisa de aproximação mais profícua entre a ciência e a sociedade. Os trabalhos que seguem essa vertente tendem a não exaurir, mas complementar os distintos aspectos teóricos do ponto de vista empirista, atrelando a observação à prática. Podemos ir além: a colocação anterior se complementa ao analisar o desequilíbrio social, a partir da concepção da própria realidade, não se tratando de situações "minadas" ou imbuídas de proposições ideologizadas, 
embora seja mais uma ação utópica que real no contexto político, social e econômico que vivenciamos.

É nesse espírito que é construído o quarto capítulo, visando compreender as relações da sociedade em massa sendo permeadas pela modernidade liberal. O trabalho passa a ser visto como uma fonte cada vez mais necessária, de riquezas e estabilidades. Robert Castel aponta ainda, para "uma transformação da concepção do trabalho, que não é mais só um dever que responde a exigências religiosas, morais ou mesmo econômicas". Torna-se então, um aparato social que deve ser orientado, estruturado e organizado, sobretudo, pela economia política (CASTEL, 2008, p. 213). Esse percurso de formação da vulnerabilidade de massa construído pelo autor nos capítulos iniciais, nos leva a repensar as situações trabalhistas nas sociedades atuais. Essa reflexão também é construída e centrada em indagações das análises investigativas que o autor propõe para a segunda parte do livro. Para tanto, é preciso nos ater às premissas que regem as dinâmicas que guiaram o processo trabalhista às configurações atuais - trabalho regulado e trabalho forçado.

O século XVIII é representado na segunda parte do livro, como o período de grandes transformações no setor industrial e trabalhista, por consequência. Contudo, Castel já chama a atenção logo no início, para os poucos avanços na condição salarial das sociedades menos favorecidas. Dessa forma, no quinto capítulo, com auxílio da Ciência Política, sobretudo, o autor discorre sobre como o Estado, enquanto aparelho político centralizador, solucionava as problemáticas envolvendo a condição salarial/trabalhista de muitas pessoas. Essa dinâmica se apresenta bastante diversificada e aquém do esperado pelos marginalizados. Se por um lado algumas ações buscavam inserir cada vez mais os trabalhadores nas condições de dependência ao setor trabalhista, por outro, quase nada era feito sobre a condição indigna no processo laboral. Essa situação se destrincha em duas vertentes, por um lado, temos o poder político e econômico centrado nas intenções utilitaristas de correções das dinâmicas capitalistas, sempre prezando por sua estrutura. Em contrapartida, temos as organizações sociais das camadas populares em busca de melhores condições sociais e econômicas, a fim de saírem dos estados de indignidade humana. O desfecho dessa nebulosa pode ser considerado evidente nessa perspectiva, pois ações emergenciais foram tomadas, a fim de minimizar a miséria da população, porém, nada além foi feito, simplesmente postergaram a problemática. Como aponta o próprio Castel, essa seria uma excelente oportunidade para se repensar as estruturas do capitalismo, todavia, não era uma questão pertinente nem positiva para os alcances exploratório que estavam por vir.

O sexto capítulo, por sua vez, se dedica a um assunto sempre atual: as mobilizações sociais em busca de seus direitos. O foco dessa análise busca entender a ruptura entre a condição de dominador e dominado ou ainda, explorados contra exploradores. Essa subversão das camadas mais populares estava centrada em uma organização mais efetiva, buscando por meio de interações coletivas e assimétricas, do próprio povo, tornar-se o Estado social - uma unidade que partia dos miseráveis, visando atender suas especificidades e direitos. Talvez o objetivo de Castel nesse capítulo, fosse de fato, apresentar o movimento de interação entre as sociedades humanas, partindo de objetivos comuns. Para tanto, vale destacar que essa concepção de mobilização social, perdurará até os dias atuais, em que os grupos desfavorecidos por alguma lógica conveniente apenas ao poder superior se manifestam e tentam seguir uma lógica centrada e excludente. Para ilustrar tal perspectiva, basta analisarmos as ondas de manifestações políticas e sociais, que eclodiram no Brasil em 2013 os protestos estavam centrados, majoritariamente, na insatisfação popular aos aumentos nas tarifas de transportes públicos (SCHERER-WARREN, 2014). Dessa forma, a partir do 
momento que a propriedade privada (no caso a renda) é afetada, toda a estrutura social é dinamicamente alterada e mobilizações sociais são acionadas.

No capítulo sete, a leitura se torna mais intensa, instigante e reflexiva, resultado de todo o arcabouço teórico acessado pelo leitor ao longo das subdivisões anteriores. Nesse ponto do texto, nos perguntamos como a condição salarial pode ser de fato vista? Mais que isso, nos colocamos em uma sala de espera e ansiedade, para preencher nossa bagagem teórica com as possíveis discussões que devam ser globalizadas, transmitidas - aplicadas em suma, nos distintos lugares que comungam dessas percepções. Para a felicidade do leitor, é a partir desse tópico que Castel analisa a condição salarial atual, e abre linhas de discussões (search fans) que dialogam profundamente com as questões trabalhistas mundiais, de modo mais específico, apresentando um campo de batalhas constantes entre a classe desfavorecida, a dinâmica capitalista e o estado.

Dado esse panorama mais geral, cabe destacar a concepção revisada da condição salarial que Castel propõe. Para ele, a relação salarial se modifica positivamente com o passar dos anos. Contudo, a dinâmica capitalista (empresas, burocratas e "proletários") procuram de formas diversificadas, estratégias para "burlar" suas obrigações básicas. Essas concepções são corroboradas e efetivadas com a anuência do poder político - que deveria estar a favor das classes menos favorecidas e excluídas (com representação em maioria). Observamos então um retorno nas condições trabalhistas, em que muitos avanços sofreram trágicos cortes e retrocessos - possuindo acesso precário, às formas mais básicas de sobrevivência, como por exemplo, "os salários mínimos que garantem apenas a sobrevivência" (alimentação) da classe trabalhadora. Os acessos aos benefícios "excedentes", como lazer, auxílios, vestimentas, moradias, etc., são o "santo graal" da condição salarial - podendo ser acessados por aqueles considerados mais aptos, competitivos e subordinados ao mercado de trabalho (CASTEL, 2008, p. 419).

Ainda neste cenário temos um complicador também de cunho social, mais propriamente dito de interações sociais. Por um lado, existem aquelas pessoas em busca de estabilidade em qualquer emprego, mesmo permanecendo no trabalho sob condições anormais, subalternas e precarizadas. Por outro lado, visualizamos as pessoas que visam atender sobretudo, a dignidade da condição salarial: que almejam ótimos cargos, melhores condições e rendas estáveis. O que une essas ramificações em uma mesma corrente, conforme apresentado por Castel, são as forças coercitivas exercidas pela esfera social de sobrevivência dos indivíduos. Nessa perspectiva, a busca por emprego está centrada na obrigatoriedade em "estar empregado", forma esta que a sociedade impõe a cada indivíduo. Essa análise que parte da obra de Robert Castel é de suma importância para se compreender as dinâmicas de mercado, que partem exatamente dessa "corrida empregatícia". O autor se torna, por assim dizer, não referência única na área, pois existem muitos outros que debatem essas questões, contudo, um importante "conector de diálogo" nas análises das interações sociais que envolvem o mercado de trabalho.

É a partir desse universo que Castel nos leva para sétimo capítulo de sua obra. O autor pressupõe que "o resultado das análises precedentes leva a interpretar a questão social tal, como se manifesta hoje, a partir do enfraquecimento da condição salarial" (p. 495). Essa tomada leva em consideração as intrínsecas relações que a situação trabalhista demonstrou ter com a sociedade, mais especificamente, o que o autor chama de instabilidade social gerada pela precariedade econômica. É chamada a atenção também, para a retomada da condição de "trabalhadores sem trabalho", vivendo marginalizados nas sociedades (p. 496). Nesse capítulo, Robert Castel faz acima de tudo, uma retomada mais global da questão trabalhista, 
dessa forma, ele observa a existência de uma nova situação social originada a partir do emprego. Essa nova roupagem, parte do crescente número de desempregados, precarização do trabalho, aumento do trabalho em tempo parcial e o surgimento da categoria "empregos ajudados" - por parte do poder público (p. 514). Este cenário é catastrófico do ponto de vista onde o desequilíbrio trabalhista assume "as rédeas" da condição salarial.

O autor elenca, ainda, a complexa situação trabalhista que vivenciamos, onde "o processo de precarização percorre algumas das áreas de emprego estabilizadas há muito tempo" - há por assim dizer, uma "desestabilização dos estáveis" (p. 526). O ambiente de trabalho se transforma em uma zona de competitividade acirrada, insegurança e aleatoriedade. Castel se arrisca a refletir sobre uma condição perdida da "identidade pelo trabalho" - análise esta que parte dos atuais contornos que envolvem a nova condição salarial (p. 531). Como processo de amarração das reflexões propostas, o autor francês apresenta as ações depreendidas pela tríade, estado, trabalhador e proprietário, para solucionar a problemática da questão salarial. Contudo, é evidente que a classe desfavorecida (organizações sociais) ainda permanece à margem das soluções efetivas. São criadas estratégias, que funcionam mais como ações emergenciais e incompletas, para resolver as problemáticas trabalhistas que custam tão caro aos empregados e/ou em busca de inserção profissional.

Esse ambiente de incertezas, metamorfoses e insatisfações que o mercado de trabalho experimenta, tendo os trabalhadores como a base que sofre diretamente essas transformações, passou por longos processos de altos e baixos. Vale destacar que os alcances positivos e fundamentais nas conquistas trabalhistas, partiram das importantes mobilizações sociais, seja por organizações, sindicatos ou coletivos. Essas são as reflexões que constituem o capítulo final (conclusão), chamado por Castel de "o individualismo negativo". Como informado anteriormente, o autor não procurou colocar um ponto final em suas análises, mas sim, esclarecer e pontuar as diversas arestas que a situação trabalhista impõe - por se tratar de um corpo que sofre metamorfoses, essa condição não se dá como findada. Nesse sentido, algumas armadilhas que espreitam essa condição precisam ser estudadas, como por exemplo, o individualismo. Talvez essa seja a maior problemática da condição salarial - uma sociedade de indivíduos que possui relações proximais enfraquecidas, e dessa forma, a organização e a luta coletiva não podem ser alcançadas.

Nesse sentido, as proposições colocadas na obra de Robert Castel elencam de forma mais incidente, as configurações sociais em suas diversas interfaces, que a análise puramente trabalhista. Esta também é uma proposição que caminha para, talvez, a única forma possível de superar a problemática salarial/trabalhista da atualidade. É por meio das coletividades, organizações, sindicatos e mobilizações, que ações efetivas serão alcançadas nesse processo de constante metamorfose da questão social/rentável.

Partir de reflexões distintas para análises aprofundadas de determinados estudos, é uma estratégia que fornece subsídios essenciais para ampliar as percepções do pesquisador. Os estudos que apresentam tais perspectivas se tornam, por assim dizer, contribuições primordiais para as temáticas que se relacionam - se tornando complementares e recorrentemente utilizados nos diversificados debates. Neste sentido, as contribuições de Castel assumem, portanto, esse papel de ligação entre as discussões que possuem a temática trabalhista como foco.

Por fim, construir um trabalho sociológico com teor interdisciplinar não é uma tarefa muito fácil, dados os atuais acessos que temos aos distintos olhares sobre o mesmo objeto. Nessa perspectiva, Robert Castel, embora tenha produzido seu livro em um contexto onde pouco, ou nada se falava de diálogos entre ciências, alcançou com louvor este desafio para a 
sua época, buscando analisar criticamente o que era expertise nos estudos permeados pelo tema trabalhista - o que torna-o modelo na busca por diálogos que vão além das "caixinhas". Sua produção contribui para reflexões da Ciência Política, Antropologia, Sociologia, Economia, Demografia, História, etc. Sem levar em consideração as distintas ramificações que existem dentro dessas ciências. As percepções de Castel atendem positivamente a um grande aparato de pesquisas empíricas ou teóricas sobre a temática em questão. Portanto, seu trabalho é uma referência interdisciplinar básica para aqueles que pretendem discutir a condição social/salarial.

\section{Referências}

CASTEL, Robert. As metamorfoses da questão social: uma crônica do salário. Tradução de Iraci D. Poleti. 7. ed. - Petrópolis, RJ: Vozes, 2008.

DOMINGUES, Ivan. Em busca do método. In: DOMINGUES, Ivan. (Org.). Conhecimento e transdisciplinaridade II: aspectos metodológicos. Belo Horizonte: Editora da UFMG, 2005.

JAPIASSU, Hilton. Interdisciplinaridade e patologia do saber. Rio: Imago Editora Ltda., 1976. $220 \mathrm{p}$.

LIBÂNEO, José Carlos. Os métodos de ensino. São Paulo: Cortez, 1994.

SALDANHA, Arthur; SILVA, Greiciele Soares da. Interdisciplinaridade no ensino superior: desafios e diálogos na educação. RELACult - Revista Latino-Americana de Estudos em Cultura e Sociedade. V. 03, nº 01, jan/abr., 2017, p. 05-16.

SCHERER-WARREN, Ilse. Manifestações de rua no Brasil 2013: encontros e desencontros na política. Caderno CRH, Salvador, v. 27, n. 71, p. 417-429, maio/ago. 2014.

SIMMEL, Georg. Soziologie, Leipzig: Duncker \& Humblot, 1908.

WEIL, Pierre. Rumo à nova transdisciplinaridade. São Paulo: Summus, 1993, 175p. 